\title{
Portable automated bag-valve mask with android technology
}

\author{
Verlyn C. Vicente*, Jesusa N. Padilla and Bartolome T. Tanguilig III \\ Graduate Programs, Technological Institute of the Philippines, Quezon City, Philippines
}

\section{(C)2016 ACCENTS}

\begin{abstract}
Automated Bag-valve mask with Android Technology is a device that allows the user to properly aid the patient with difficulty in breathing. The device is capable of providing the patient with the right amount of air and constant flow rate air delivery, replacing the manual bag-valve that requires at least two people to operate effectively. The device consistently pumps the prescribed amount of oxygen to patients, depending on age and is designed to be portable and be carried on emergency responses for pre-hospital care.
\end{abstract}

\section{Keywords}

Bag-valve Mask, Resuscitation, Ventilation, Pre-hospital care.

\section{Introduction}

The use of a bag-valve device is a required part of resuscitation kits for trained professionals in out-ofhospital settings and most cases inside the hospital. There are two principal types of manual resuscitator one is self-filling with air, although additional oxygen can be added but is not necessary for the device to function. While the other one is flowinflation that is heavily used in non-emergent applications in the operating room to ventilate patients during anaesthesia induction and recovery [1]. However, because the bag-valve requires a constant manual pumping by the operator, it does not guarantee a consistent air delivery on the patient. As a result, bag valve devices are being linked to high incidents of hyper-ventilation, which greatly affects cardiac arrest patients, patients with traumatic brain injuries, and as well as patients that are under the state of shock. Instances, where an excess pressure supplied to a patient may result in rupturing of lungs[2].

The current solution to the problems brought by the manual pumping of bag valve is the bulky automated ventilation machines that are about $10-25 \mathrm{kgs}$ in weight and costs thousands of dollars [3]. These are used in the hospital in replacement of bag valves to give a steady flow of air delivery to the patients. However, these machines are not only costly to operate but are only available for use of a specific number of patients due to its cost.

\footnotetext{
*Author for correspondence
}

These machines are only present on hospitals and are not carried on ambulances that respond on emergencies where it is highly needed.

\section{Basic principle and system structure}

\subsection{System structure}

The design of the prototype is one of the considerations in defining the mobility of the automated bag-valve. The following segments show how the device is controlled and how the system works.

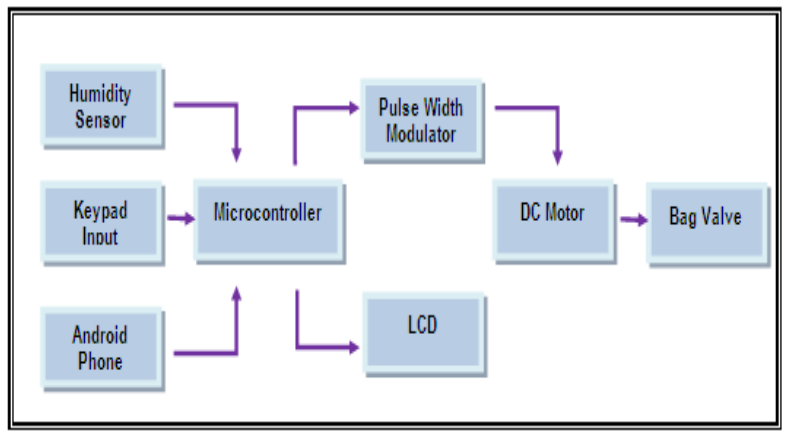

Figure 1 Block diagram of the system

Shown on Figure 1 is the block diagram of the system where the microcontroller will accept input from the keypad on the device and the humidity sensor connected to it. When the device is wished to be controlled remotely, the input will come from the Android phone that is connected to the device using Bluetooth connection. The microcontroller will trigger the pulse width modulator and will simultaneously convey the output on the LCD. The 
pulse width modulator will regulate the DC motor with the pre-configured setting and will then control piston for the accurate pumping of the bag-valve.

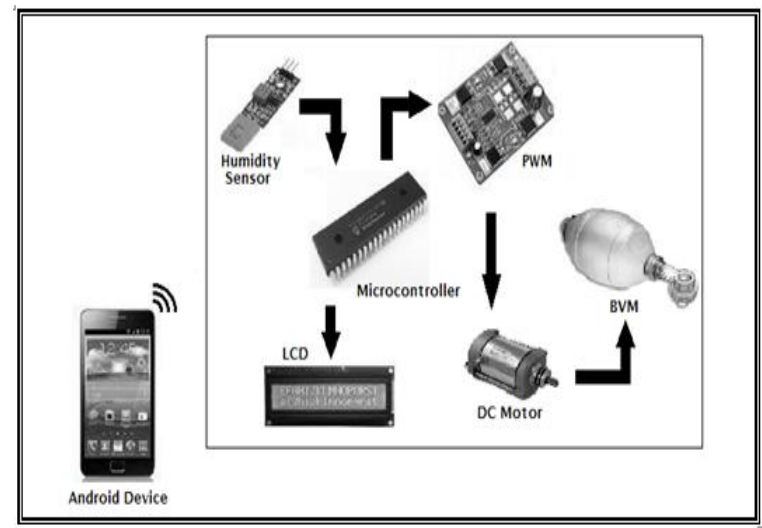

Figure 2 System architecture of portable automated bag-valve mask
Figure 2 displays the graphical representation of the intended components of the system and the relationship of each. The PIC16F877A was designed as the computer of the device while a Pulse Width Modulator as the motor driver. This is a necessary technique to maintain the overall uptime of the design[4]. The PWM will only be powered when it is used to run the motor while the PIC16F877A is always powered on.

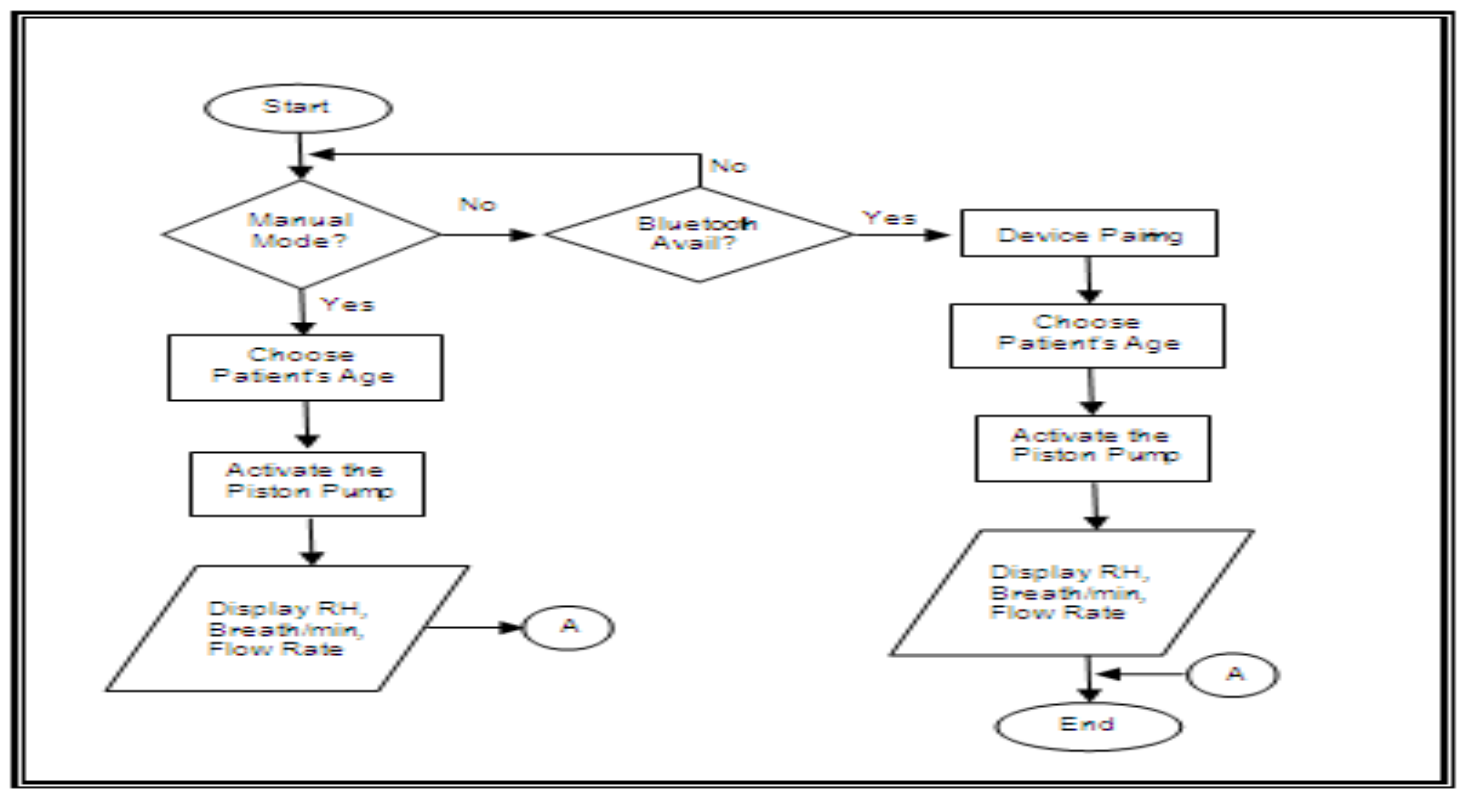

Figure 3 System flowchart

After turning on the device, it will then prompt the user whether to operate on manual mode or through an Android device shown on Figure 3. If the manual mode is selected, the user will then have to choose whether the patient is within the age bracket of an adult or a child. The input will then trigger the piston pump to operate according to the programmed rate on the microcontroller for the desired output of air flow based on standard flow rate for an adult or a child. The same process goes when the device is wished to be controlled on an Android device, but it has to be connected first via Bluetooth. If the device fails to detect a nearby Bluetooth connection, the process will be repeated, asking the user whether to operate on manual mode or through Android.

\subsection{Prototype design}

The design uses a piston-type pumping mechanism powered by a single DC motor and a rectangular case that housed the entire mechanism, circuit and bagvalve device. The rectangular design was taken into account to mate the design compact and small in size. This type of case design also ensures the efficient pumping of the piston mechanism that pumps the 
bag-valve device as shown in Figure 4. The inputted values were based on computations for the piston to function properly[5].

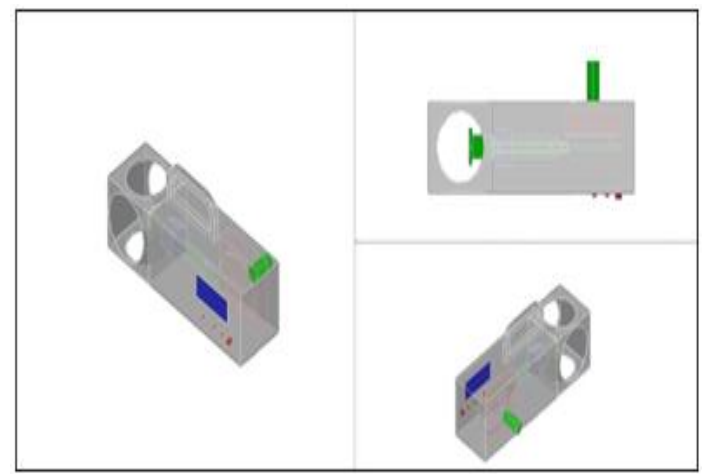

Figure 4 Prototype design using piston pump

The motor gesture is calibrated so that the pumping mechanism does not exceed the needed amount to supply a 12 volt DC motor operates the mechanism and provides the means to pump the bag-valve. The piston pump replicates the movements of the human hand closer than any type of mechanism. The humidity sensor monitors the humidity of the air being pump to the patient. The monitoring of humidity was used to prevent complication to the patient because of the dry air being pumped. The Bluetooth Shield transmits the data towards the receiving device which is the Android Device. The Android application processes the given data and the inputted values. The data represented in digital form according to its measuring parameters.

\subsection{System algorithm}

The design uses a system that is divided into three parts; the Android application, the software coded into the PIC16F877A in charge of the communication with the Android application through Bluetooth and in interpreting user inputs along with the output of the humidity sensor. The software for the Android application was coded using the MIT App Inventor 2 and $\mathrm{C}$ programming to program the software embedded in the microcontroller. The computation of relative humidity done by the humidity sensor is not readily in digital form.

Once a relative humidity measurement has been made, the results of the measurement may be converted to percent relative humidity by using the following expression which relies on the RH_Code, a 16-bit word returned by the sensor:
$\% R H=\frac{125 * \mathrm{RH}_{\text {Code }}}{65536}-6$

Where: $\% \mathrm{RH}$ is the measured relative humidity value in $\% \mathrm{RH}$

Once the calculation has been made, the relative humidity is presented in percentage. This is used for displaying the measured parameter on the device's LCD and on the Android application. The microcontroller unit's software acted as an interface between the Android application, humidity sensor, and pulse width modulator for the DC motor and the LCD screen that display data processed by the device. The Android application sends information based on the data inputted by the user which will be transmitted over the Bluetooth channel. The input and output to and from the Android will be fed into port 25 and 26 which is respectively the RX and TX of the PIC16F877A. Based on the PIC16F877X data sheet, the RX and TX port must be connected to the TX and RX ports of the Bluetooth shield. This lets the ports of the microcontroller and the Bluetooth shield to communicate with each other by listening to what each has to send over their connection.

The TX port of the microcontroller sends data gathered from the sensor as well as data from the calculations and other parameters while the RX of the Bluetooth shield receives these data and transmits them via Bluetooth to a paired device. The RX of the microcontroller is connected to the TX of the shield to listen to the commands from the Android application (paired Bluetooth device). The received command varies with each a different course of action. The OK command pairs the Android device with the ventilation device. The DATA: 1 command is to initialize adult age bracket operation. DATA: 2commandsare to initialize child age bracket operation. DATA: 3interrupt and stop the running operation and reset both the ventilation device and the Android application.

\subsection{Graphical user interface design}

The Graphical User Interface was developed using Android application software. In MIT App Inventor, an Android Emulator ran to test and to simulate the Android application that created. To ensure the connection between the Android application and the prototype, it needs to have a range of 10 meters based on the IEEE 802.15.1 Standard for Bluetooth. 


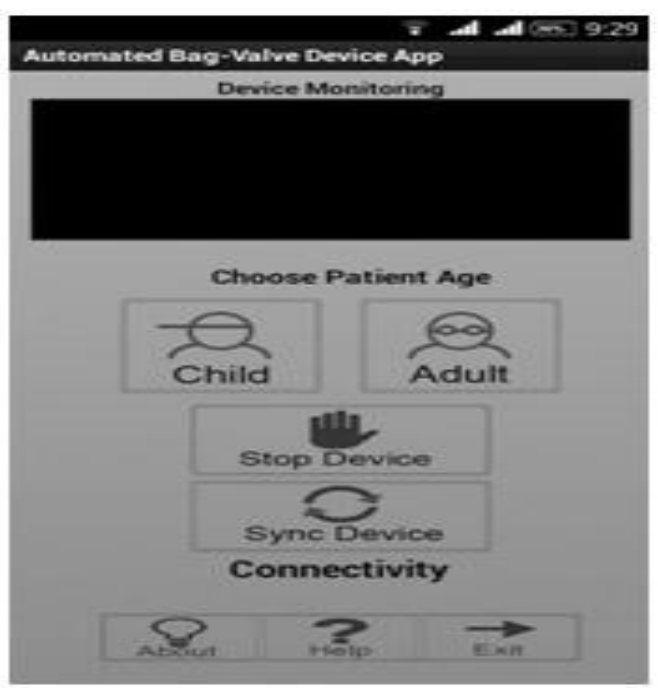

Figure 5 Graphical user interface of the android application

In the Figure 5 shown is the GUI or the Graphical User Interface of the Android application. It also shows the control window of the application which is connected to the prototype after syncing. This section is where the user will choose the mode for the patient namely Adult and Child, to initialize pumping pattern. It also has a connectivity status to indicate the connection to the prototype. The Sync Device button turns on the Bluetooth of the device to establish a connection to the prototype. Adult and Child is the mode to select to initialize proper pumping for both modes.

Figure 6 shows the display from the device. It shows the current rate of pumping and the percentage of the humidity present.

\begin{tabular}{l}
\multicolumn{1}{c}{ Device Monitoring } \\
Type: Adult. RH:59.1\% \\
Breath(s):12/min \\
FlowRate:408.9mL/Pump
\end{tabular}

Figure 6 Values displayed on the android device

\section{Methods}

\subsection{Test procedures}

Testing procedures are consists of methods and scenarios in a controlled environment, wherein all present variables are simulated with the aid of the clinical study which states the standard pumping of oxygen using the bag-valve-mask[6]. The procedures conducted in the testing include the testing of the software, hardware, reliability and accuracy and are all describe listed below:

\subsubsection{Software test}

The software will be tested based on the specific objective that is to monitor and control the device. The testing has been conducted to determine if the Android application display results based on the mode chosen by the user on the device.

3.1.2Accuracy test

The testing for the accuracy of the design will be conducted through the percentage accuracy formula shown below.

Percentage Accuracy

$$
=\left(\frac{\text { MeasuredValue }}{\text { Actual Value }}\right) \times 100
$$

The measured value is the value displayed in the Android application as discussed in the Graphical User Interface layout while the actual value is the value taken through the standard value[7][8]. The measured parameters for the accuracy include the number of second per pump and breathe per minute. The testing of the system will be done by examining the results of the system ten times for the adult and ten times for the child.

\section{Results and discussion}

\subsection{Accuracy test result}

The accuracy was calculated based on the results obtained on these aspects; the accuracy of the flow rate and breath per minute for adult and flow rate and breathe per minute for a child.

\subsubsection{For adult}

The tables in this section are the accuracy of the values generated compared to the standard time (number of seconds) per pump for an adult of the bag-valve-mask. It tests the consistency of the pumping providing stable amount of air to the patient. The values of the Percentage Accuracy of seconds per pump on the following tables were taken by averaging the number of second/pump to the measured number of second/pump and the Average Accuracy were taken by averaging by the values in Percentage Accuracy.

Table 1 Results for number of seconds/pump compared to measured number of seconds/pump (adult)

\begin{tabular}{cccc}
\hline Trial & $\begin{array}{c}\text { Number of } \\
\text { second/pump }\end{array}$ & $\begin{array}{c}\text { Measured } \\
\text { number of } \\
\text { second/pump }\end{array}$ & $\begin{array}{c}\text { Percentage } \\
\text { accuracy }\end{array}$ \\
\hline 1 & 5 & 4.89 & $97.8 \%$ \\
2 & 5 & 4.70 & $94 \%$ \\
3 & 5 & 4.70 & $94 \%$ \\
4 & 5 & 4.81 & $96.2 \%$ \\
\hline
\end{tabular}




\begin{tabular}{llll}
\hline Trial & $\begin{array}{c}\text { Number of } \\
\text { second/pump }\end{array}$ & $\begin{array}{c}\text { Measured } \\
\text { number of } \\
\text { second/pump }\end{array}$ & $\begin{array}{c}\text { Percentage } \\
\text { accuracy }\end{array}$ \\
\hline 5 & 5 & 4.84 & $96.8 \%$ \\
& \multirow{2}{*}{ Average Accuracy } & $95.76 \%$ \\
\hline
\end{tabular}

The Number of Second/Pump on Table 1 refers to the standard number of second/pump for adult[7][8]. The Measured Numbers of Seconds/Pump are the values obtained on counting during testing. The values for Percentage Accuracy have been taken through the formula for percentage accuracy given in the Accuracy Test. The following shows the calculations for the values of Percentage Accuracy and Average Accuracy of Table 1.

The result of Average Accuracy, using equation 2, for number of second/pump is $95.76 \%$ and is more than $95 \%$ (as the standard percentage for accuracy), therefore the number of second/pump values generated by the device with respect to the standard values for adult given is accurate.

Table 2 Results for breath per minute (adult)

\begin{tabular}{cccc}
\hline Trial & Time & $\begin{array}{c}\text { Breath/ } \\
\text { Minute }\end{array}$ & Remarks \\
\hline 1 & $1: 00: 48$ & 12 & Accurate \\
2 & $1: 00: 67$ & 12 & Accurate \\
3 & $00: 59: 37$ & 12 & Accurate \\
4 & $1: 03: 01$ & 12 & Accurate \\
5 & $00: 59: 74$ & 12 & Accurate \\
\hline
\end{tabular}

The values on Table 2 show the result of Breath per Minute for the adult which is 12breaths/minute[7]. Each trial will be marked "Accurate" if the value of the breath per minute is ranging 10-12. The time shows the specific time after the bag-valve-mask got the value of 12 .

The values in the Pump Count on Table 3 refers to the standard value that the bag-valve-mask can pump to fill a 2000ml Oxygen Reservoir Bag.

Table 3 Results for pump count compared to measured pump count for a $2000 \mathrm{ml}$ oxygen reservoir bag

\begin{tabular}{llll}
\hline Trial & $\begin{array}{l}\text { Pump } \\
\text { Count } \\
(\mathbf{2 0 0 0} \text { MI) }\end{array}$ & $\begin{array}{l}\text { Measured } \\
\text { Pump } \\
\text { Count }\end{array}$ & $\begin{array}{l}\text { Percentage } \\
\text { Accuracy }\end{array}$ \\
\hline $\mathbf{1}$ & 5 & 5 & $100 \%$ \\
$\mathbf{2}$ & 5 & 5 & $100 \%$ \\
$\mathbf{3}$ & 5 & 4.5 & $90 \%$ \\
$\mathbf{4}$ & 5 & 5 & $100 \%$ \\
$\mathbf{5}$ & 5 & 5 & $100 \%$ \\
Average Accuracy & & $98 \%$ \\
\hline
\end{tabular}

The Measured Pump Counts are the values obtained during the testing by means of manual counting. The result of Average Accuracy for pump count is 98\% and is more than $95 \%$ (as the standard percentage for accuracy), therefore the pump count generated by the system with respect to the values measured during testing through manual counting are accurate.

4.1.2For child

The tables in this section are the accuracy of the values generated compared to the standard number of seconds per pump for child of the bag-valve-mask. It tests the consistency of the pump to provide stable amount of air to the patient. The values of the Percentage Accuracy of second per pump on the following tables were taken by averaging the number of second/pump to the measured number of second/pump and the Average Accuracy were taken by averaging by the values in Percentage Accuracy.

Table 4 Results for number of seconds/pump compared to measured number of seconds/pump (child)

\begin{tabular}{cccc}
\hline Trial & $\begin{array}{c}\text { Number of } \\
\text { Second/ } \\
\text { Pump }\end{array}$ & $\begin{array}{c}\text { Measured } \\
\text { Number of } \\
\text { Second/Pump }\end{array}$ & $\begin{array}{c}\text { Percentage } \\
\text { Accuracy }\end{array}$ \\
\hline 1 & 3 & 2.97 & $99 \%$ \\
2 & 3 & 3.00 & $100 \%$ \\
3 & 3 & 2.91 & $97 \%$ \\
4 & 3 & 3.00 & $100 \%$ \\
5 & 3 & 2.95 & $98.33 \%$ \\
& Average Accuracy & $98.87 \%$ \\
\hline
\end{tabular}

The Number of Second/Pump on Table 4 refers to the standard number of second/pump for child[7]. The Measured Numbers of Second/Pump are the values obtained on counting during our testing. The values for Percentage Accuracy have been taken through the formula for percentage accuracy. The following shows the calculations for the values of Percentage Accuracy and Average Accuracy of Table 4. The result of Average Accuracy for number of second/pump is $98.87 \%$ and is more than $95 \%$ (as the standard percentage for accuracy), therefore the number of second/pump values generated by the device with respect to the standard values for child given is accurate.

Table 5 Results for breath per minute (child)

\begin{tabular}{llll}
\hline Trial & Time & Breath/Minute & $\begin{array}{l}\text { Remark } \\
\text { S }\end{array}$ \\
\hline 1 & $1: 01: 60$ & 20 & Accurate \\
2 & $1: 02: 07$ & 20 & Accurate \\
3 & $1: 01: 59$ & 20 & Accurate \\
4 & $1: 01: 74$ & 20 & Accurate \\
5 & $1: 02: 16$ & 20 & Accurate \\
\hline
\end{tabular}


The values on Table 5 show the result of Breath per Minute for the child which is 20 breaths/ minute [7] [9]. Each trial will be marked "Accurate" if the value of the breath per minute is 20 . The time shows the specific time after the bag-valve-mask got the value of 20 .

Table 6 Results for pump count compared to measured pump count for a $2000 \mathrm{ml}$ oxygen reservoir bag

\begin{tabular}{cccc}
\hline Trial & $\begin{array}{c}\text { Pump } \\
\text { Count } \\
(\mathbf{2 0 0 0} \mathbf{~ M l})\end{array}$ & $\begin{array}{c}\text { Measured } \\
\text { Pump } \\
\text { Count }\end{array}$ & $\begin{array}{c}\text { Percentage } \\
\text { Accuracy }\end{array}$ \\
\hline $\mathbf{1}$ & 7 & 7 & $100 \%$ \\
$\mathbf{2}$ & 7 & 6.5 & $95 \%$ \\
$\mathbf{3}$ & 7 & 7 & $100 \%$ \\
$\mathbf{4}$ & 7 & 6.5 & $95 \%$ \\
$\mathbf{5}$ & 7 & 7 & $100 \%$ \\
& Average Accuracy & & $98 \%$ \\
\hline
\end{tabular}

The values in the Pump Count on Table 6 refers to the standard value the bag-valve-mask can pump to fill a 2000ml Oxygen Reservoir Bag. The Measured Pump Count is the values obtained during the testing by means of manual counting. The value for the Percentage Accuracy has been calculated through the formula for Percentage Accuracy given in the Accuracy Test in this chapter. The calculation below shows how to arrive on Percentage Accuracy and Average Accuracy of Table 6. The result of Average Accuracy for pump count is $98 \%$ and is more than 95\% (as the standard percentage for accuracy), therefore the pump count generated by the system with respect to the values measured during testing through manual counting are accurate.

\subsection{Reliability test result}

The reliability of the system was tested according to testing procedure stated in terms of hardware failure based on the consistency of the system to generate accurate results.

4.2.1For adult

The table below shows the values taken from the testing conducted and the standard values for bagvalve-mask for the flow rate in Adult Mode.

Table 7 Results for reliability test for adult

\begin{tabular}{lcccccccccc}
\hline Trial & $\mathbf{1}$ & $\mathbf{2}$ & $\mathbf{3}$ & $\mathbf{4}$ & $\mathbf{5}$ & $\mathbf{6}$ & $\mathbf{7}$ & $\mathbf{8}$ & $\mathbf{9}$ & $\mathbf{1 0}$ \\
\hline No. of Sec/Pump & 5 & 5 & 5 & 5 & 5 & 5 & 5 & 5 & 5 & 5 \\
Measured No. of & 4.89 & 4.70 & 4.70 & 4.81 & 4.84 & 4.90 & 5 & 4.80 & 4.98 & 4.78 \\
$\begin{array}{l}\text { Sec/Pump } \\
\text { Pump Count }\end{array}$ & 5 & 5 & 5 & 5 & 5 & 5 & 5 & 5 & 5 & 5 \\
Measured Pump Count & 5 & 5 & 4.5 & 5 & 5 & 5 & 4.5 & 5 & 4.5 & 5 \\
Ave Accuracy /Trial & 98.9 & 97 & 92 & 98.1 & 98.4 & 99 & 95 & 98 & 93.9 & 97.8 \\
\hline
\end{tabular}

The testing of the device has been conducted to test the consistency of the number of seconds per pump, breath per minute and the flow rate of the bag-valvemask for adult. Trials were conducted with 1 hour interval. The Average Accuracy value per trial has been calculated using equation 3 :

$$
\left.\frac{\left\{\left[\left(\frac{\text { Number of } \frac{\text { Seconds }}{\text { Pump }}}{\text { Measured Number of } \frac{\text { Seconds }}{\text { Pump }}}\right) \times 100\right]+\right.}{\left[\left(\frac{\text { Pump Count }}{\text { Measured Pump Count }}\right)\right] \times 100}\right\}
$$

The device was able to consistently generate values up to tenth trial; therefore the system is reliable in terms of its hardware failure. The device didn't easily get affected by such error.

4.2.2For Child:

Table 7 shows the values taken from the testing conducted and the standard values for bag-valvemask for the flow rate in Child Mode.

The testing of the device has been conducted to test the consistency of the number of seconds per pump, breath per minute and the flow rate of the bag-valve mask for child. Trials were conducted with 1 hour interval. The Average Accuracy value per trial has been calculated using equation number 3 . 
Verlyn C. Vicente et al.

Table 8 Results for reliability test for child

\begin{tabular}{lcccccccccc}
\hline Trial & $\mathbf{1}$ & $\mathbf{2}$ & $\mathbf{3}$ & $\mathbf{4}$ & $\mathbf{5}$ & $\mathbf{6}$ & $\mathbf{7}$ & $\mathbf{8}$ & $\mathbf{9}$ & $\mathbf{1 0}$ \\
\hline No. of Sec/Pump & 3 & 3 & 3 & 3 & 3 & 3 & 3 & 3 & 3 & 3 \\
$\begin{array}{l}\text { Measured No. of } \\
\text { Sec/Pump }\end{array}$ & 2.97 & 3.00 & 2.91 & 3.00 & 2.95 & 2.90 & 3.00 & 2.98 & 2.88 & 3.00 \\
$\begin{array}{l}\text { Pump Count } \\
\text { Measured Pump }\end{array}$ & 7 & 7 & 7 & 7 & 7 & 7 & 7 & 7 & 7 & 7 \\
$\begin{array}{l}\text { Count } \\
\text { Ave Accuracy /Trial }\end{array}$ & 99.5 & 96.5 & 7 & 6.5 & 7 & 7 & 6.5 & 6.5 & 7 & 7 \\
\hline
\end{tabular}

The device was able to consistently generate values up to tenth trial; therefore the system is reliable in terms of accuracy.

\section{Conclusion}

From findings obtained mentioned in results and discussion, it is concluded that the study is truly acceptable in providing the patients with the accurate amount of air and constant flow air delivery replacing the manual bag-valve that requires at least two people to operate effectively.

The device consistently pumps the prescribed amount of air to patients, depending on age and is designed to be portable for it to be carried on emergency responses for pre-hospital care. The validations of the results of testing were compared to standards.

The device uses an Android application that controls the mode of the device and displays the current amount of air with each pump in terms relative humidity of air supplied. It functions in accordance to the parameter that is set by the user, which is the age bracket of the patient, which will determine the amount of air and the number of breaths per minute needed by the patients.

The functionality of the device is limited in supplying the required amount of air for patients on the age bracket of child and adult. The device can also be connected to an Android device that will serve as another interface for the user, using Bluetooth connection within a maximum range of 10 meter radius.

\section{Acknowledgment}

None.

\section{Conflicts of interest}

The authors have no conflicts of interest to declare.

\section{References}

[1] Hirshon JM. Chapter 12: Basic cardiopulmonary resuscitation in adults. Emergency medicine: a comprehensive study guide. 6th Edition. Tintinalli JE, Kelen GD, Stapczynski JS (Ed). McGraw-Hill Publishing; 2004.

[2] William P, Wiesmann M. Dangers of Bag Valve Masks Respiratory and Airway Management, 2011.

[3] Walls RM, Murphy MF, editors. Manual of emergency airway management. Lippincott Williams \& Wilkins; 2008.

[4] Lin J, inventor; Lin, Jimmy, assignee. Auto-pumping unit for bag-valve-mask resuscitator. United States patent US 20,050,284,472. 2005.

[5] Fogarty M, Orr J, Westenskow D, Brewer L, Sakata D. electric blower based portable emergency ventilator; 2013.

[6] Buttaravoli P. Bag-mask ventilation. Annals of emergency medicine. 1986; 15(1):108.

[7] http://www.acep.org/clinical-practice/. Accessed 12 May 2015.

[8] Reichman E. Emergency medicine procedures. McGraw Hill Professional; 2013.

[9] Mead HJ. Pediatric Emergency Medicine: A comprehensive study guide. Emergency Medicine. 1996;8(1):42-3.

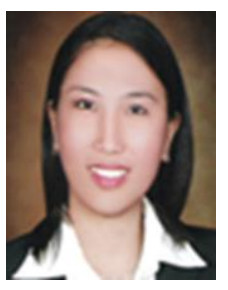

Verlyn C. Vicente was born on March 30, 1988 in Marikina City Philippines. She is currently taking up her Master of Engineering Program with specialization in Computer Engineering at Technological Institute of the Philippines. She is currently affiliated with the Philippine Society of IT Educators (PSITE) and Institute of Computer Engineers of the Philippines (ICpEP).

Email: verlyn.vicente@gmail.com 


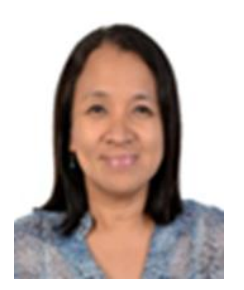

Dr. Jesusa N. Padilla holds degrees in Doctor of Technology from the Technological University of the Philippines (TUP) and Master of Engineering major in Computer Engineering from the Pamantasan ng Lungsod ng Maynila (PLM) and is currently the Dean of the College of Engineering and Architecture of the Technological Institute of the Philippines, Quezon City. She was a member of the Technical Advisory Committee of DOST-PCIERD (Philippine Council for Industry and Energy Research and Development) and member of the Technical Working Group (Energy and Food Sectors) DOST-NCR MMIERDC (Metropolitan Manila Industry and Energy Research and Development Consortium). She is a Professional Electronics Engineer and an ASEAN Engineer and had experience in the electronics industry as a design engineer.

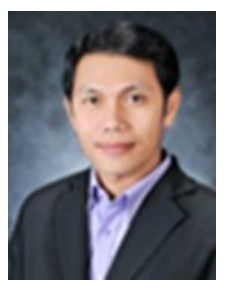

Dr. Bartolome T. Tanguilig III is currently the Assistant Vice President for Academic Affairs and concurrent Dean of the Graduate Programs of the Technological Institute of the Philippines, Quezon City. Dr. TanguiligIII is a member of the Commission on Higher Education (CHED) Technical Panel for IT Education (TPITE), the chair of the CHED Technical Committee for IT (TCIT), the founder of Junior Philippine ITE Researchers (JUPITER), Vice President - Luzon of the Philippine Society of IT Educators (PSITE), board member of the PCS Information and Computing Accreditation Board (PICAB), member of the Computing Society of the Philippines (CSP) and a program evaluator / accreditor of the Philippine Association of Colleges and Universities Commission on Accreditation (PACUCOA). 